Bull. Mater. Sci., Vol. 36, No. 1, February 2013, pp. 93-97. (c) Indian Academy of Sciences.

\title{
New observations on formation of thermally induced martensite in $\mathrm{Fe}-30 \% \mathrm{Ni}-1 \% \mathrm{Pd}$ alloy
}

\author{
GOKCEN YILDIZ*, YASIN GOKTURK YILDIZ and SAFFET NEZIR \\ Department of Physics, Science and Arts Faculty of Kirikkale University, 71450 Yahsihan, Kirikkale, Turkey
}

MS received 20 September 2011; revised 10 April 2012

\begin{abstract}
Kinetical, morphological, crystallographical and thermal characteristics of thermally induced martensite in an Fe-30\% Ni-1\% Pd alloy has been studied by scanning electron microscopy (SEM), transmission electron microscopy (TEM), differential scanning calorimetry (DSC) and X-ray diffraction method. Kinetics of transformation was found to be as athermal. SEM and TEM observations and X-ray method revealed $\alpha^{\prime}($ bcc $)$ martensite formation in the austenite phase of alloy by thermal effect. The crystallographic orientation relationship between austenite and $\alpha^{\prime}(b c c)$ martensite was found to be having Kurdjumov-Sachs (K-S) type relationship. In addition, the lattice parameters of austenite and martensite phases were calculated from X-ray diffraction patterns.
\end{abstract}

Keywords. Fe-Ni-Pd alloy; martensitic transformations; electron microscopy; X-ray diffraction; athermal kinetics.

\section{Introduction}

Among materials scientists, there is continual interest in studying martensite and martensitic transformation. This is dictated by some beneficial properties of the martensite products (Nishiyama 1978; Krauss 1990; Bhadeshia 2004; Han and $\mathrm{Xu}$ 2006). Early studies on the formation of martensite in different ferrous alloys revealed that the formation mechanism and substructure of martensite are considerably altered by the transformation temperature, alloy composition, strengths of the material in the austenite and martensite phases, cooling rate of the matrix structure during the transformation and the austenite stacking fault energy in addition to the well known effects of the austenite grain size and the formation sequence of the martensitic structures (Davies and Magee 1971; Thomas 1971; Krauss and Marder 1971; Durlu 2001).

Martensitic transformation on cooling begins at the $M_{\mathrm{S}}$ temperature; the extent of transformation progressively increases with lowering of temperature and it is completed, finally attaining complete transformation at the temperature, $M_{\mathrm{f}}$, which is known as the martensite finish temperature (Banerjee and Mukhopadhyay 2007). In many of the martensitic transformations discussed so far, the reactions start at the $M_{\mathrm{s}}$ temperature and proceed while the temperature is falling. When the cooling is stopped, the reaction stops and when the cooling is resumed, they start again. The reactions proceed only when the temperature is changing (Nishiyama 1978). Therefore, martensite produced by this type of reaction is referred to as athermal martensite. In some cases,

\footnotetext{
*Author for correspondence (gkcndikici@ hotmail.com)
}

however, martensites form isothermally above or below the $M_{\mathrm{s}}$ temperature. This type of martensite is referred to as isothermal martensite (Nishiyama 1978).

The diffusionless $f c c(\gamma) \rightarrow b c c\left(\alpha^{\prime}\right)$ transformation in $\mathrm{Fe}-$ $\mathrm{Ni}$ alloys has been the subject of the numerous investigations (Chilton and Kelly 1968; Maki et al 1984). The morphology of the resulting martensite depends on the $M_{\mathrm{s}}$ temperature, alloy chemistry, austenite yield strength and stacking fault energy (Sridharan et al 1991). Addition of Mn, Cr, Ti, etc as third alloying elements to binary $\mathrm{Fe}-\mathrm{Ni}$ alloys alters some aspects of martensitic transformations. Especially, kinetics of transformation, morphology and crystallography of the existing martensite show a distinct variety because of the above different alloying elements (Kato and Mori 1976; Hall and Winchell 1977; Kakeshita et al 1993; Visvesvaran 1996).

Although many studies are present for thermally induced martensite in various $\mathrm{Fe}-\mathrm{Ni}-\mathrm{X}$ alloys, no work has been reported for the $\mathrm{Fe}-30 \% \mathrm{Ni}-1 \% \mathrm{Pd}$ alloy. Therefore, the present study was to examine morphology, crystallography and martensite kinetics of thermally induced martensite in $\mathrm{Fe}-\% 30 \mathrm{Ni}-\% 1 \mathrm{Pd}$ alloy by SEM, TEM, DSC and X-ray diffraction methods.

\section{Experimental}

The alloy employed in the present study was $\mathrm{Fe}-30 \% \mathrm{Ni}-$ $1 \% \mathrm{Pd}(\mathrm{wt} \%)$ which was prepared by vacuum induction melting under an argon atmosphere from pure (99.9\%) alloying elements. This alloy was having the shape of cylindrical bars $(1 \mathrm{~cm}$ diameter and $10 \mathrm{~cm}$ long). Bulk samples were 
homogenized at $1100{ }^{\circ} \mathrm{C}$ in quartz tube for $6 \mathrm{~h}$ and then quenched in water at room temperature. These samples were then mechanically thinned for SEM observations. The surface of the samples was mechanically polished and used as chemical solution which contained $90 \mathrm{ml}$ $\mathrm{H}_{2} \mathrm{O}_{2}, 15 \mathrm{ml} \mathrm{H}_{2} \mathrm{O}$ and $5 \mathrm{ml} \mathrm{HF}$ for clarifying samples surfaces. Surface studies of samples were carried out using a JEOL JSM 5600 type scanning electron microscope with $20 \mathrm{kV}$ operating voltage. New thin foil samples $(\sim 50 \mu \mathrm{m})$ were prepared for transmission electron microscopy from the thermally treated samples. These TEM specimens were then electropolished at room temperature using a twin-jet polishing technique with a solution of $150 \mathrm{ml}$ 2-butoxy ethenol, $50 \mathrm{ml}$ of perchloric acid and $300 \mathrm{ml}$ methanol. TEM observations were performed by a JEOL 3010 type TEM with $300 \mathrm{kV}$ operating voltage. In order to determine $M_{\mathrm{s}}, A_{\mathrm{s}}$ and $A_{\mathrm{f}}$ temperatures of transformation in $\mathrm{Fe}-30 \% \mathrm{Ni}-1 \% \mathrm{Pd}$ alloy, homogenized samples of this alloy were prepared in the shape of $1 \mathrm{~mm}$ diameter discs and encapsulated in aluminum pans. DSC samples of this alloy were performed by using a Perkin-Elmer Sapphire model thermal analyser and taken at a cooling rate of $5{ }^{\circ} \mathrm{C} / \mathrm{min}$ between 20 and $-150{ }^{\circ} \mathrm{C}$.

\section{Results and discussion}

Figure 1(a) shows secondary electron image of SEM micrograph of the austenite phase of $\mathrm{Fe}-30 \% \mathrm{Ni}-1 \% \mathrm{Pd}$ alloy with its typical austenite grain boundaries. Figure 1(b) shows a SEM micrograph of this sample after $5 \mathrm{~s}$ liquid nitrogen $\left(-196^{\circ} \mathrm{C}\right)$ immersion. This thermal stimulation caused martensite plates formation in figure 1(b).

Martensite start temperatures $\left(M_{\mathrm{s}}\right)$ of martensite transformation $\left(\gamma \rightarrow \alpha^{\prime}\right)$ was determined by differential scanning calorimetry (DSC) measurements as $-33{ }^{\circ} \mathrm{C}$ (figure 2a). Some evidences such as new nucleation sites or growth of existing martensite crystals achieved by further isothermal martensitic transformations are well descriptioned by Kajiwara (1992). Although sample of the $\mathrm{Fe}-30 \% \mathrm{Ni}-1 \% \mathrm{Pd}$ alloy were kept at $-196{ }^{\circ} \mathrm{C}$ for $10 \mathrm{~min}, 10 \mathrm{~h}$ and 10 days, these isothermal holding times did not cause the formation of martensite crystals. This application suggests that the martensite kinetics displayed athermal type. On the other hand, austenite start $\left(A_{\mathrm{s}}\right)$ and finish temperature $\left(A_{\mathrm{f}}\right)$ of transformation were also determined as $360{ }^{\circ} \mathrm{C}$ and $450{ }^{\circ} \mathrm{C}$, respectively (figure $2 \mathrm{~b}$ ) from DSC measurements.

As a remarkable result, $A_{\mathrm{s}}$ and $A_{\mathrm{f}}$ did not show a major deviation with addition of $1 \% \mathrm{Pd}$ to $\mathrm{Fe}-30 \% \mathrm{Ni}$ binary alloy when compared with Kaufman's previous study (table 1) on $\mathrm{Fe}-30 \cdot 7 \% \mathrm{Ni}$ alloy (Kaufman and Cohen 1956). On the other hand, previous results have been reported that, addition of $\mathrm{Cr}$, Mo and $\mathrm{Si}$ as a third alloying element to binary $\mathrm{Fe}-\mathrm{Ni}$ alloys, the $M_{\mathrm{s}}$ temperatures of thermally induced martensites were determined as $-138{ }^{\circ} \mathrm{C}$ for $\mathrm{Fe}-29.40 \% \mathrm{Ni}-2 \% \mathrm{Cr}$ alloy (Visvesvaran 1996), $-180{ }^{\circ} \mathrm{C}$ for $\mathrm{Fe}-28 \% \mathrm{Ni}-7.5 \% \mathrm{Si}$ alloy (Himuro et al 2002) and $-83{ }^{\circ} \mathrm{C}$ for $\mathrm{Fe}-30 \% \mathrm{Ni}-0.8 \% \mathrm{Mo}$
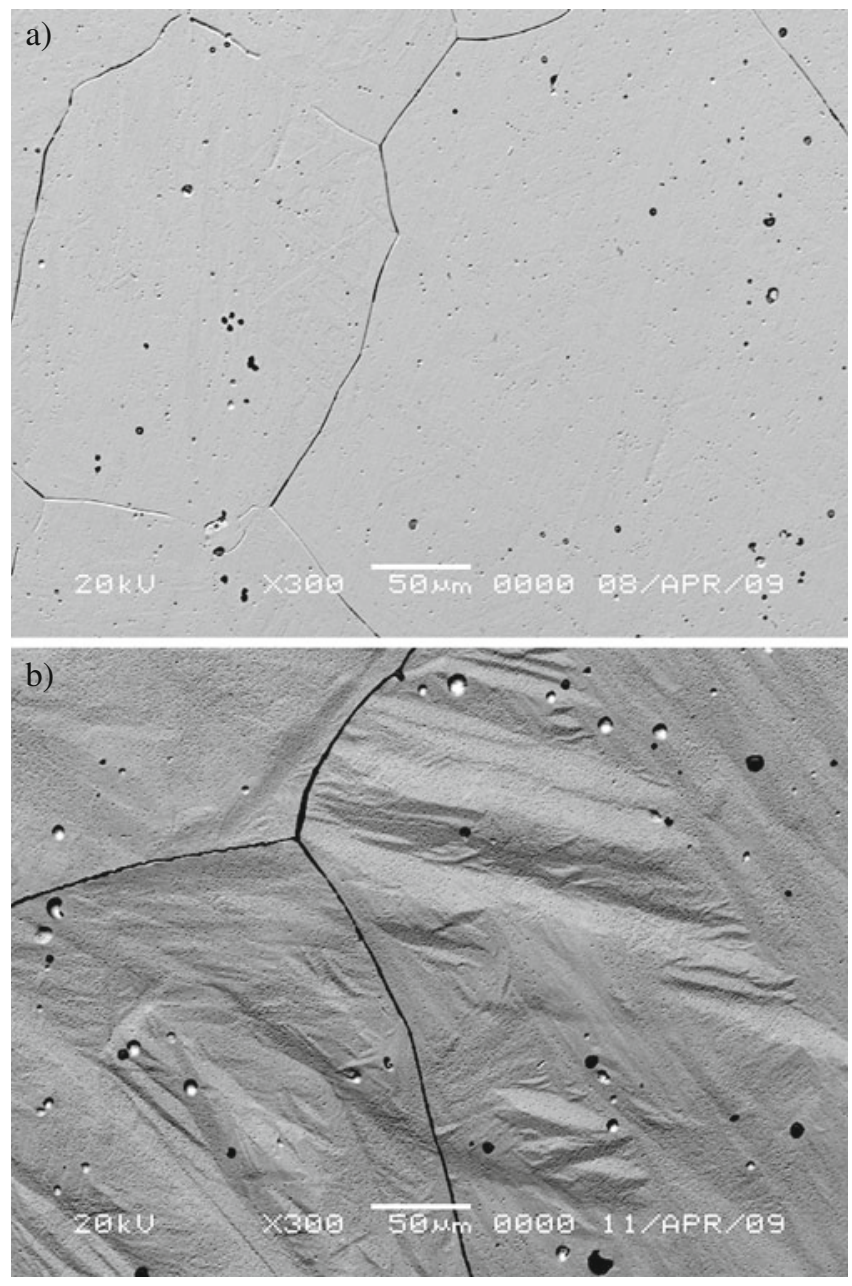

Figure 1. SEM micrographs showing microstructure of $\mathrm{Fe}-$ $30 \% \mathrm{Ni}-1 \% \mathrm{Pd}$ alloy: (a) austenite phase which has typical grain boundaries and (b) surface relief of martensite plates formed on immersing in liquid nitrogen.

alloy (Yasar et al 2006). According to the present study, compared with the other elements $(\mathrm{Cr}, \mathrm{Si}, \mathrm{Mo})$, the element of $\mathrm{Pd}$ increases the temperature of $M_{\mathrm{s}}$.

TEM observations revealed that in the examined $\mathrm{Fe}-$ $30 \% \mathrm{Ni}-1 \% \mathrm{Pd}$ alloy the austenite matrix transforms to $\alpha^{\prime}$ martensite. It is well known that the martensitic transformation nucleation starts at dislocations (Nishiyama 1978). Figure 3 shows TEM micrograph of a typical dislocation network in $\mathrm{Fe}-30 \% \mathrm{Ni}-1 \% \mathrm{Pd}$ alloy.

In ferrous alloys five types of $b c c$ (or $b c t$ ) martensite morphologies have been observed: lath, butterfly, plate, lenticular and thin-plate (Maki 1990). The martensite morphology depends on the alloy composition or the formation temperature. Each morphology is different in crystallography and substructure (Maki 1990; Shibata et al 2009). Exemplary, $\mathrm{Fe}-\mathrm{Ni}-\mathrm{Ti}$ alloys with a $\mathrm{Ni}$ content in the range 27 to $30 \mathrm{wt} \%$ form martensite i.e. tetragonal crystal structure (Whiteman and Sarma 1974). Also, addition of Mo to binary $\mathrm{Fe}-30 \% \mathrm{Ni}$ alloys, martensite morphology was changed from 

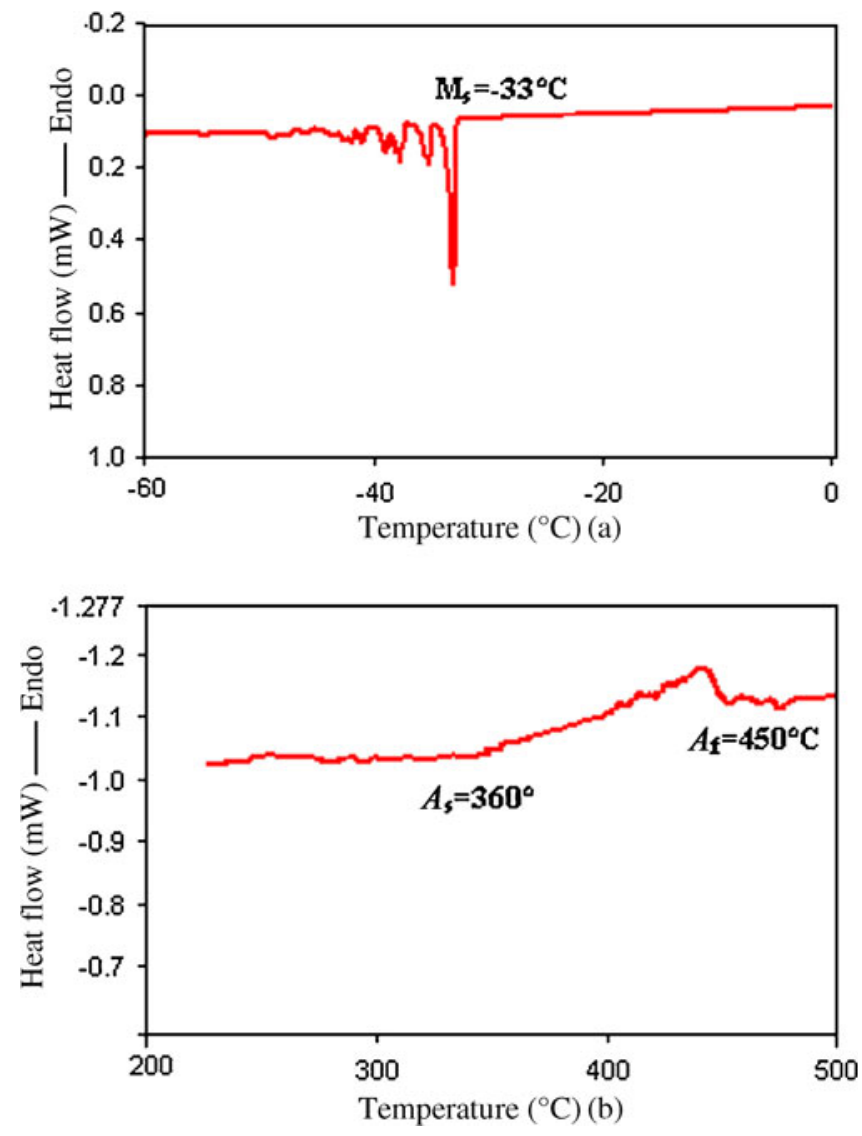

Figure 2. (a) DSC curves showing $M_{\mathrm{S}}$ temperature of thermally induced martensite in $\mathrm{Fe}-30 \% \mathrm{Ni}-1 \% \mathrm{Pd}$ alloy and (b) $A_{\mathrm{S}}$ and $A_{\mathrm{f}}$ temperatures of thermally induced martensite in $\mathrm{Fe}-30 \% \mathrm{Ni}-1 \% \mathrm{Pd}$ alloy.

Table 1. DSC results of previous and present studies.

\begin{tabular}{lccc}
\hline Sample (wt $\%)$ & $M_{\mathrm{S}}\left({ }^{\circ} \mathrm{C}\right)$ & $A_{\mathrm{s}}\left({ }^{\circ} \mathrm{C}\right)$ & $A_{\mathrm{f}}\left({ }^{\circ} \mathrm{C}\right)$ \\
\hline $\mathrm{Fe}-30 \% \mathrm{Ni}-1 \% \mathrm{Pd}$ (present study) & -33 & 360 & 450 \\
$\mathrm{Fe}-30 \cdot 7 \% \mathrm{Ni}$ (Kaufman's study) & -42 & 365 & 435 \\
\hline
\end{tabular}

martensite crystal having internal twins to $\varepsilon$-martensite with increasing Mo content (Yasar et al 2007). The present study shows that, addition of Pd element to binary Fe-30\% Ni alloy, the austenite matrix transforms to $\alpha^{\prime}$-martensite. Figure 4 shows that the present observations indicate that this typical morphology may also appear in the thermally induced martensite plate of an Fe-Ni-Pd alloy. In addition, selected area electron diffraction pattern of austenite-martensite interface and matching key diagram of this pattern can be seen in figure 4(b).

It is well known that three different orientation relationships (i.e. Kurdjumov-Sachs (K-S), NishiyamaWassermann (N-W), and Greninger-Troiano (G-T)) between the martensite and the parent phase (austenite) have

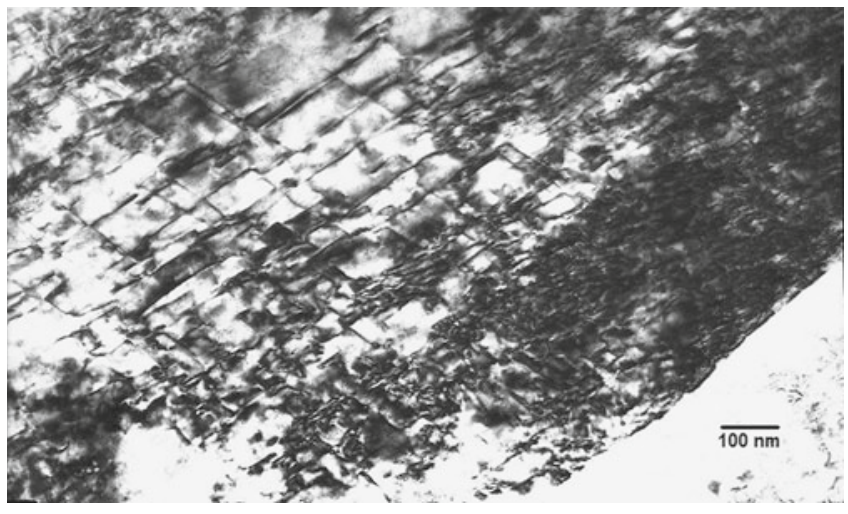

Figure 3. TEM micrograph of a typical dislocation network in austenite phase in $\mathrm{Fe}-30 \% \mathrm{Ni}-1 \% \mathrm{Pd}$ alloy.
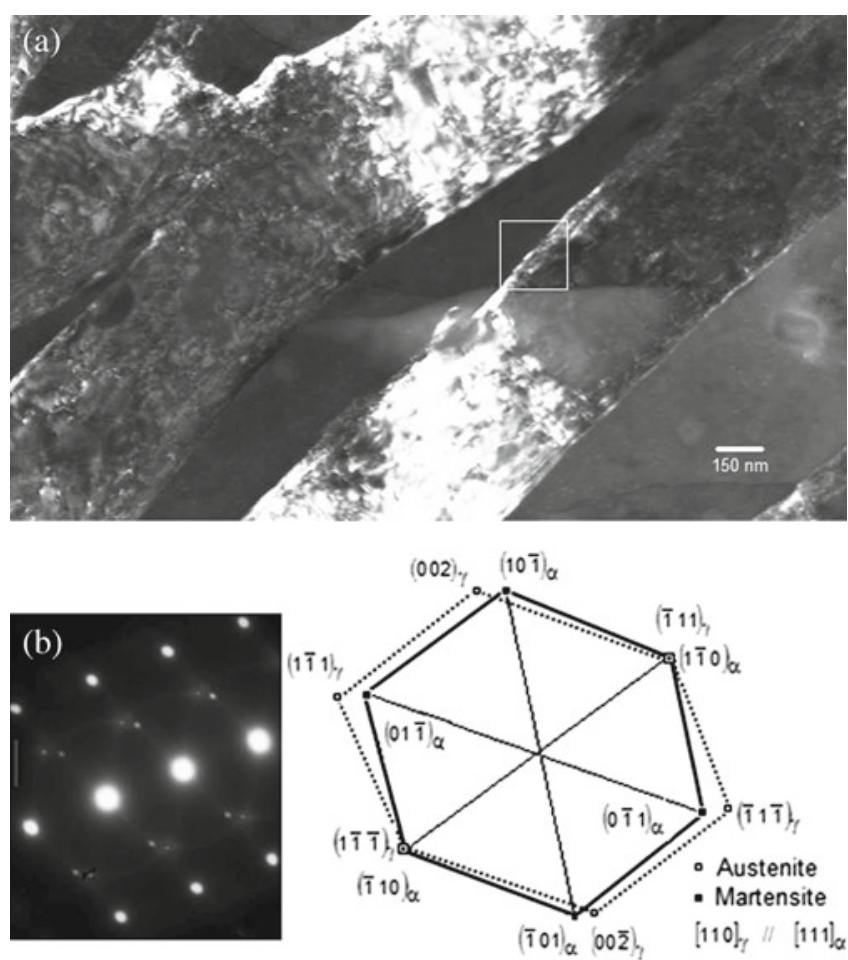

Figure 4. (a) Dark-field electron micrograph of athermal plate martensite and (b) selected area (indicated with a square) electron diffraction pattern and corresponding key diagram.

been reported in $\mathrm{Fe}-\mathrm{Ni}$ alloys (Nishiyama 1978). It is quite obvious from figure 4(b) that the crystallographic orientation relationship between the austenite and thermally induced plate martensite crystals shows a typical $(1 \overline{1} 0)_{\alpha^{\prime}} / /(\overline{1} 11)_{\gamma}$, $[111]_{\alpha^{\prime}} / /[110]_{\gamma}$ Kurdjumov-Sachs $(\mathrm{K}-\mathrm{S})$ type and the habit plane is determined as very close to $[252]_{\gamma}$ plane of the austenite. These crystallographic results of study display appropriate behaviours with respect to earlier reports (Yang and Wayman 1992; Yasar et al 2007). Moreover, figure 5 (a-b) shows a TEM micrograph of a martensite formation 

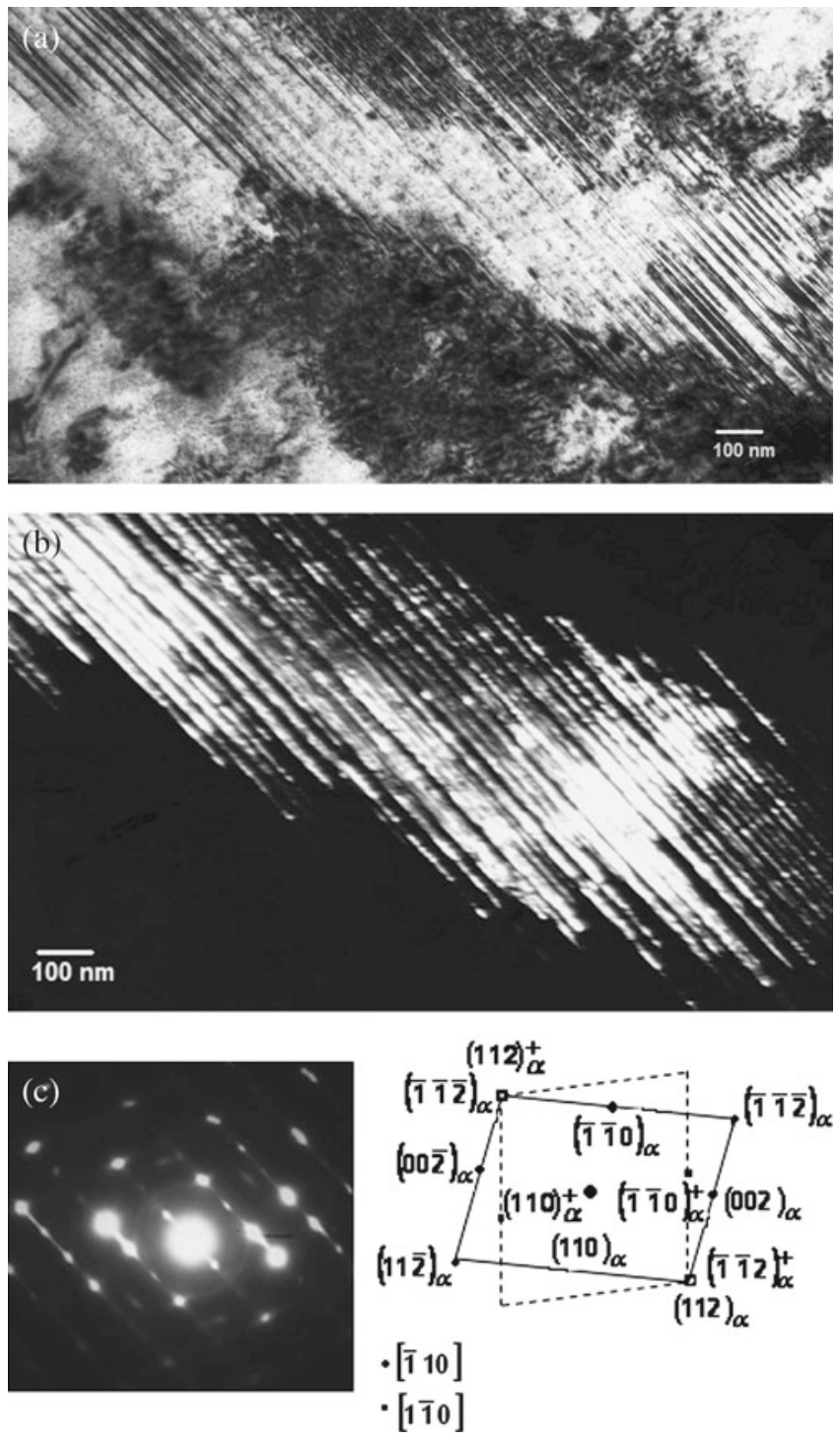

Figure 5. (a) Bright, (b) dark field electron micrographs of martensite plate with twinning and (c) electron diffraction pattern of selected area.

with twinning. In addition, figure 5(c) shows selected area electron diffraction pattern of this twinning and its corresponding indices. The electron diffraction pattern consists of two sets of reflections which correspond to the [1]10] and $[1 \overline{1} 0]^{t}$ zone of the martensite crystals structure. The observed existence of the dense twinning on $\{112\}_{\alpha^{\prime}}$ planes consisted of the predictions of the crystallographic theories (Wechsler et al 1953; Bowles and Mackenzie 1954; Mackenzie and Bowles 1954, 1957).

Crystal structures of alloy specimens were confirmed by X-ray diffraction measurement. Diffraction patterns of $\mathrm{X}$-ray were also given in figure 6 . As shown in figure 6, X-ray diffraction patterns exhibit the $f c c(\gamma)$ and $b c c\left(\alpha^{\prime}\right)$ peaks. The mean values of the lattice parameter of the austenite and

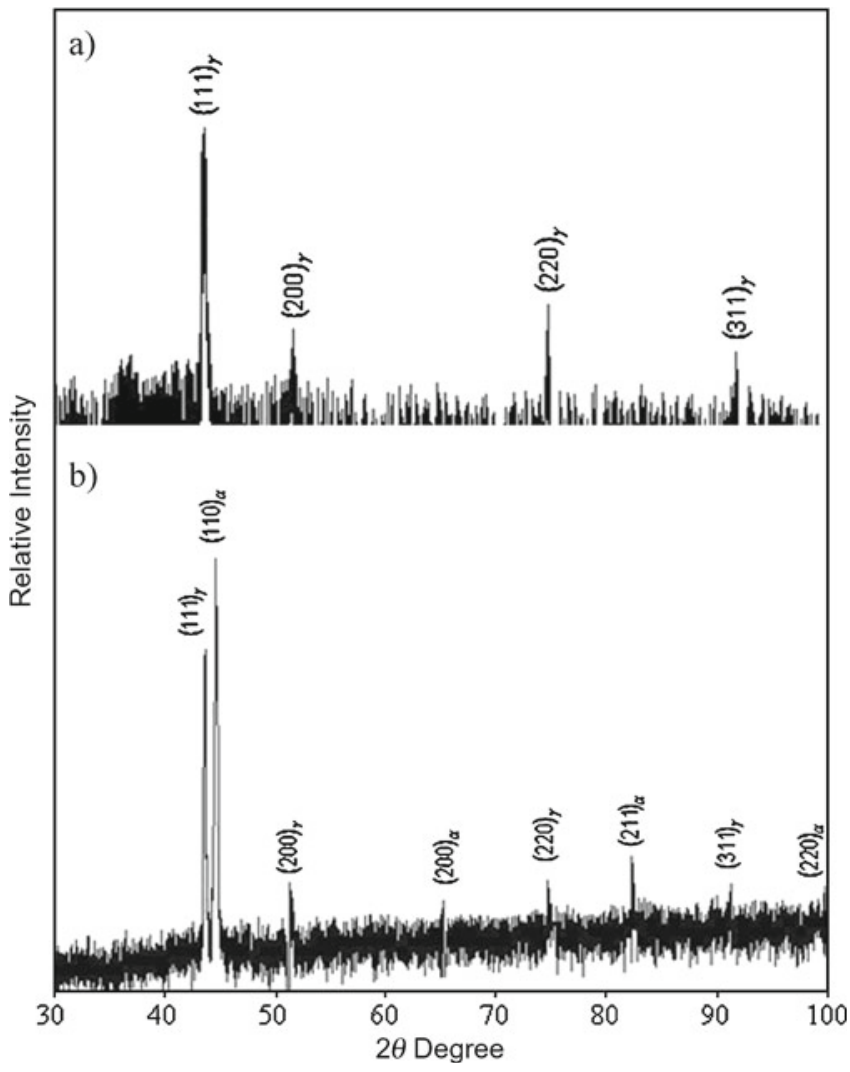

Figure 6. X-ray diffraction patterns for each specimen of $\mathrm{Fe}-$ $30 \% \mathrm{Ni}-1 \% \mathrm{Pd}$ alloy: (a) specimen quenched in water and at room temperature and homogenized at $1100^{\circ} \mathrm{C}$ for $6 \mathrm{~h}$ and (b) specimen after $5 \mathrm{~s}$ liquid nitrogen $\left(-196^{\circ} \mathrm{C}\right)$ immersion.

martensite phases were calculated as $3 \cdot 5712 \AA$ and $2 \cdot 8615 \AA$, respectively. The results of X-ray experiments agree with TEM and SEM observations.

\section{Conclusions}

The main findings of the present study can be summarized as:

(I) According to DSC results, $A_{\mathrm{s}}, A_{\mathrm{f}}$ and $M_{\mathrm{s}}$ temperatures do not display a major deviation with addition of $1 \% \mathrm{Pd}$ to $\mathrm{Fe}-30 \%$ Ni binary alloy and the $\gamma \rightarrow \alpha^{\prime}$ transformation kinetics found as athermal, viz. martensitic phase transformation displayed the burst phenomenon in the studied alloy.

(II) From a morphologic viewpoint, thermally induced martensite exhibits plate morphology in the $\mathrm{Fe}-30 \% \mathrm{Ni}-$ $1 \% \mathrm{Pd}$ alloy and the crystallographic orientation between the austenite phase and thermally induced martensite exhibited a $\mathrm{K}-\mathrm{S}$ type orientation relationship.

(III) Plate-like martensite in $\mathrm{Fe}-\mathrm{Ni}-\mathrm{Pd}$ alloys is associated with internal transformation twins.

(IV) The observed $\{112\}_{\alpha^{\prime}}$ internal twins are of the proper variant to be the transformation twins of the phenomenological theory. 
(V) X-ray measurement on thermally induced martensite confirmed both SEM and TEM observations of $\alpha^{\prime}(b c c)$ martensite formation.

\section{Acknowledgement}

This work is supported by the Kirikkale University Research Project (2008/17).

\section{References}

Banerjee S and Mukhopadhyay P 2007 Phase transformations, Pergamon Materials Series pp 277-278

Bhadeshia H K D H 2004 Mater. Sci. Eng. A378 34

Bowles J S and Mackenzie J K 1954 Acta Metall. 2 129, 224

Chilton J M and Kelly P M 1968 Acta Met. 16637

Davies R G and Magee C L 1971 Metall. Trans. B2 1939

Durlu T N 2001 J. Mater. Sci. 365665

Hall M M and Winchell P G 1977 Acta Metall. 25735

Han B and Xu Z 2006 Mater. Sci. Eng. A431 109

Himuro Y, Kainuma R and Ishida K 2002 ISIJ Int. 42184

Kajiwara S 1992 Mater. Trans. JIM 331027

Kakeshita T, Kuroiwa K, Shimizu K, Ikeda T, Yamagishi A and Date M 1993 Mater. Trans. JIM 34415
Kato M and Mori T 1976 Acta Metall. 24853

Kaufman L and Cohen M 1956 Trans. AIME J. Metals 206 1393

Krauss G and Marder A R 1971 Metall. Trans. B2 2343

Krauss G 1990 Steels heat treatment and processing principles (Ohio: ASM International)

Mackenzie J K and Bowles J S 1954 Acta Metall. 2138

Mackenzie J K and Bowles J S 1957 Acta Metall. 5137

Maki T 1990 Mater. Sci. Forum 56157

Maki T, Kobayashi K, Minato M and Tamura I 1984 Scr. Met. 18 1105

Nishiyama Z 1978 Martensitic transformation (London: Academic Press) pp 1, 239

Shibata A, Morito S, Furuhara T and Maki T 2009 Acta Mater. 57 483

Sridharan K, Worzala F J and Dodd R A 1991 Mater. Chem. Phys. 30115

Thomas G 1971 Metall. Trans. B2 2373

Visvesvaran P 1996 Metall. Mater. Trans. A27 973

Wechsler M S, Lieberman D S and Read T A 1953 Trans. AIME J. Metals 1971503

Whiteman J A and Sarma S 1974 Metall. Trans. 5163

Yang J H and Wayman C M 1992 Mater. Charact. 2823

Yasar E, Gungunes H, Kilic A and Durlu T N 2006 J. Alloys Compd 42451

Yasar E, Gungunes H, Akturk S and Durlu T N 2007 J. Alloys Compd $\mathbf{4 2 8} 125$ 